\title{
Centchroman use in dysfunctional and abnormal uterine bleeding after $\mathrm{D}$ and $\mathrm{C}$
}

\author{
Piyusha Chandrayan*, Foram H. Naik, Deepak A. Desai
}

Department of Obstetrics and Gynecology, Sumandeep Vidyapeeth University, Vadodara, Gujarat, India

Received: 09 July 2018

Revised: 26 July 2018

Accepted: 27 July 2018

\section{*Correspondence:}

Dr. Piyusha Chandrayan,

E-mail: piyusha011@gmail.com

Copyright: (c) the author(s), publisher and licensee Medip Academy. This is an open-access article distributed under the terms of the Creative Commons Attribution Non-Commercial License, which permits unrestricted non-commercial use, distribution, and reproduction in any medium, provided the original work is properly cited.

\begin{abstract}
Background: Incidence of DUB is more in the age group of 30-35yr and is about 35\%-40\%. Medical management (Centchroman) can be the treatment of preference, after excluding any organic pathology in uterus. To evaluate efficacy and side effects of Saheli (Centchroman) in case of dysfunctional uterine bleeding will depend upon the type of endometrium as determined histologically after minor procedure, D\&C (Dilatation and Curettage). This drug will be used only in the presence of Proliferative Endometrium on Histopathological Examination.

Methods: The study was carried out at Dhiraj Hospital, Piparia. It was an Interventional Study. 50 patients were studied in 6 months of period, 25 each of DUB and AUB. A total of 50 patients were enrolled in this study, who were attending or were admitted in the hospital. Patients who meet the inclusion criteria were included in this study, after taking prior written and informed consent.

Results: Most of the patient were in the age group 39-45 years. The common complaint was excessive uterine bleeding, for which they were prescribed Centchroman. Most of the DUB patients were relieved on medication. However, few of them who had poor response to drug went for hysterectomy. It was observed that patients with early proliferative phase on HPE had better response to this drug as compared with late proliferative phase. All the patients with late proliferative phase underwent hysterectomy. Most patient with AUB including Fibroid, Adenomyosis, Endometrial hyperplasia had little or no response went for hysterectomy sooner or later on after therapy in $50 \%$ cases. Centchroman is relatively a safe drug. The most common side effect encountered was breakthrough spotting in 15 patients. 4 patients complained of amenorrhoea after 3 months of taking this drug and 1 patient complained of itching and rash over the body. No major complications were noted.

Conclusions: Centchroman can be an effective non hormonal drug used for menorrhagia with proliferative endometrium with early changes in patients of DUB. This drug can also be used to control menorrhagia in patients with fibroid. This is also beneficial in patients with menorrhagia with medical illness to avert hysterectomy.
\end{abstract}

Keywords: Abnormal uterine bleeding, Centchroman, Dysfunctional uterine bleeding, Dilatation and curettage

\section{INTRODUCTION}

"DUB" (Dysfunctional uterine bleeding) is defined as abnormal bleeding from the uterus, in the absence of demonstrable structural or organic disease. Incidence of DUB is more in the age group of $30-35 \mathrm{yr}$ and is about $35 \%-40 \%$.
Abnormal uterine bleeding (AUB) may display several patterns, and descriptive terms have been updated to standardize nomenclature (Munro, 2011). ${ }^{2}$ For example, heavy menstrual bleeding (HMB) (formerly menorrhagia) defines prolonged or heavy cyclic menstruation. Objectively, menses lasting longer than 7 days or exceeding $80 \mathrm{~mL}$ of blood loss are determining values. ${ }^{1}$ 


\section{Differential diagnosis of abnormal bleeding}

- Structural anomaly- Uterine-leiomyoma, adenomyosis, endometrial polyp, endometrial hyperplasia or cancer, uterine sarcoma

- AVM Cervix-endocervical polyp, dysplasia, or cancer. Vagina-cancer, postoperative granulation tissue. Fallopian tube-cancer Ovary-sex cord-stromal tumors, Atrophic vaginal, cervical, or endometrial epithelia. Partial outflow obstruction-congenital müllerian defect.

- Anovulation due to Immature HPO axis or aging ovarian follicles hypothyroidism, hyperprolactinemia. Pituitay or hypothalamic disorder- Androgen excess-PCOS, CAH, Cushing syndrome/disease, Premature ovarian failure

- Pregnancy related e.g.- Implantation, abortion, ectopic pregnancy, GTD

- Exogenous e.g.-IUD, foreign body, trauma Medications-sex steroids, anticoagulants.

- Infection e.g.-STD, TB, chronic endometritis, postabortal or postpartum infection

- Systemic abnormalities eg-Coagulopathies, hepatic or chronic renal failure, hyperthyroidism, obesity $(\mathrm{CAH}=$ congenital adrenal hyperplasia; GTD = gestational trophoblastic disease; HPO = hypothalamic-pituitary-ovarian axis; PCOS = polycystic ovarian syndrome; STD = sexually transmitted disease; $\mathrm{TB}=$ tuberculosis)

Medical management tried with (SAHELI), contains active ingredient Centchroman. This can be the treatment of preference, after ruling out any abnormal pathology in uterus. Centchroman is the world's first Non-steroidal oral contraceptive pill.

Introduced in 1991 by Central Drug Research Institute, Lucknow. It is a selective estrogen receptor modulator, with weak Estrogenic and Potent anti-estrogenic action. It was used in India, initially for contraception purpose in 1 lakh women, due to it's inhibitory action on uterus during implantation. It doesn't disturb endocrine system and normal ovulatory cycle is maintained. It is devoid of side effect of hormonal pill and the contraceptive property is reversible. It is used in the dosage of Single tablet of (30mg) twice a week for 3 months followed by once a week for till the contraception is desired.

Only side effect observed with this drug is delayed menstrual cycle, which is around $8 \%{ }^{3}$

MOA -The contraceptive action of Saheli (Centchroman) is caused by asynchrony created in preparing the uterus for implantation. This asyncrony is caused by:

- Accelerated tubal transport of embryo,

- Accelerated blastocyst formation,

- Delayed zona shedding,

- Suppression of uterine decidualisation.

\section{Contraindications}

- Polycystic ovarian disease

- Cervical hyperplasia

- As it is recommended, with all medications, same is said for Centchroman-recent history of clinical evidence of jaundice or liver disease, Severe allergic states, chronic illnesses such as tuberculosis, renal diseases. $^{3}$

As per studies, it can be used in Dysfunctional uterine bleeding, osteoporosis and Pre-menstrual syndrome.4 Its use in osteoporosis is due to its weak oestrogenic action on bones as it has Selective Oestrogen Receptor Modulator action. Its use in Dysfunctional uterine bleeding and Abnormal uterine bleeding will depend upon the type of endometrium as determined histologically after minor procedure, D and C (Dilatation and Curettage).

This drug is used only in the presence of proliferative endometrium on histopathological examination. The presence of proliferative endometrium depicts stromal breakdown, decreased spiral arteriole density and dilated unstable venous capillaries. This leads to severe bleeding, due to impaired prostaglandins and Arachidonic acid. In such cases, Saheli (Centchroman) remedies the problem by it's suppressive effect on endometrium

This study aims to solve the problem of DUB and AUB by medical management by Saheli, given for 6 months. Patients were called for follow up visit, twice, after every 3 months. This study also aims to assess the effect of Saheli in the management of DUB and AUB and to try to establish an effective non-hormonal treatment modality.

\section{METHODS}

The study was carried out at Dhiraj Hospital, Piparia. It was an Interventional Study. 50 patients were studied in 6 months of period, 25 each of DUB and AUB. A total of 50 patients was enrolled in this study, who were attending or were admitted in the hospital. Patients who meet the inclusion criteria were included in this study, after taking prior written and informed consent.

\section{Inclusion criteria}

- All women having menorrhagia categorized under dysfunctional uterine bleeding undergoing Dilatation and Currettage, with Proliferative phase of endometrium in the HPE report.

- Women having a demonstrable uterine pathology as a reason for excessive bleeding with preferably proliferative endometrium after D and C. This group included only uterine fibroid, adenomyosis, endometrial hyperplasia patients.

\section{Exclusion criteria}


- Patients with heavy bleeding necessitating emergency treatment.

- Women with a known, suspected or with a history of genital tract malignancy.

\section{Method of collection}

Women with the diagnosis of DUB and AUB based on clinical and ultrasound findings, who underwent endometrial sampling/curettage were recruited for this study along with normal routine investigations. How-ever after reviewing the histo-pathology report of the sampled endometrium, those having proliferative endometrium, was treated with "Saheli" (Centchroman). The tablet was prescribed twice a week at the dosage of $30 \mathrm{mg}$, for a period of 3 months followed by $30 \mathrm{mg}$ once a week for next 3 months. The patients with mostly proliferative phase of endometrium on histopathology report were prescribed this drug. Follow up visits were done at 3 months and 6 months, after initiating treatment with Saheli (Centchroman).

\section{RESULTS}

Figure 1 shows equal number of patients taken in both AUB and DUB study group i.e. 50\%.

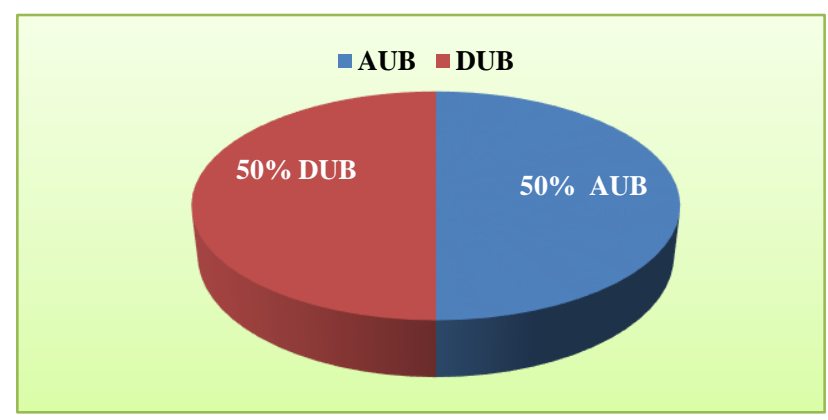

Figure 1: Percentage of DUB and AUB patients.

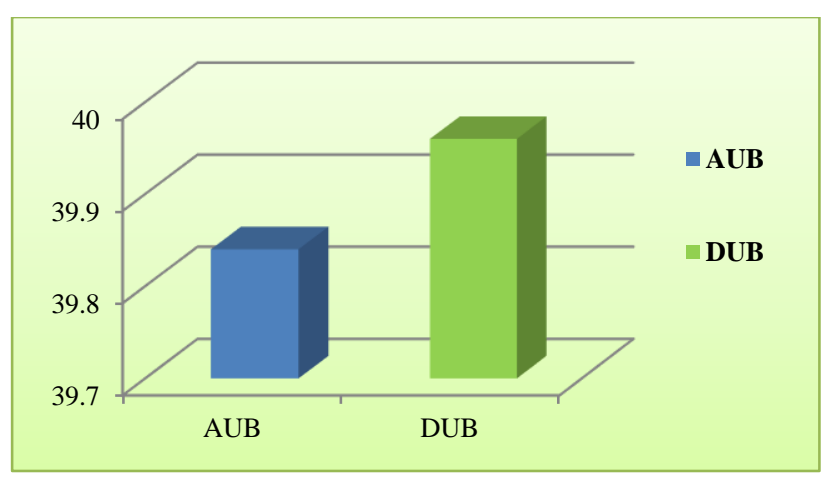

Figure 2: Percentage of DUB and AUB patients.

As per Figure 2 the mean age was around 40 years in both groups.

Table 1: Percentage of patients rom (relieved on medication) in AUB and DUB group.

\begin{tabular}{|llll|}
\hline Diagnosis & ROM & $\%$ & p value \\
\hline AUB & 6 & $25.00 \%$ & \\
\cline { 1 - 2 } DUB & 18 & $75.00 \%$ & 0.014 \\
\hline Total & 24 & $100.00 \%$ & (significant) \\
\hline
\end{tabular}

In Table 1 most of the DUB patients, $75 \%$ were relieved on medication whereas in AUB group only $25 \%$ patients found effect of this drug on their symptoms.

Table 2: Percentage of patients who underwent hysterectomy in AUB and DUB group.

\begin{tabular}{|llll|}
\hline Diagnosis & Hysterectomy & $\%$ & p value \\
\cline { 1 - 2 } AUB & 17 & 77.27 & \\
\cline { 1 - 2 } DUB & 5 & 22.73 & 0.011 \\
\cline { 1 - 2 } Total & 22 & 100.00 & (significant) \\
\hline
\end{tabular}

As per Table 2 few of them who had poor response to drug went for hysterectomy which was nearly $23 \%$ in DUB group and $77 \%$ in AUB group.

Table 3: The histopathology report of patients who underwent hysterectomy in DUB group.

\begin{tabular}{|lllll|}
\hline DUB & N & Percentage & & HPE (hysterectomy) \\
\hline Early proliferative & 18 & 78 & ROM & \\
\hline Late proliferative phase & 5 & 22 & hysterectomy & Endometrium- proliferative phase \\
\hline
\end{tabular}

Table 4: The histopathology report of patients who underwent hysterectomy in AUB group.

\begin{tabular}{|lccl|}
\hline AUB & N (hysterectomy) & Percentage & HPE (hysterectomy) \\
\hline Fibroid & 5 & 29.4 & $\begin{array}{l}\text { Endometrium- } \\
\text { proliferative,myometrium- } \\
\text { leiomyoma, chronic cervicitis }\end{array}$ \\
\hline Adenomyosis & 10 & 58.8 & Myometrium- adenomyotic changes \\
\hline Endometrial hyperplasia & 2 & 11.7 & Hyperplasia without atypia \\
\hline
\end{tabular}


As shown in Table 3, it was observed that patients with early proliferative phase, $78 \%$ on HPE had better response to this drug as compared with late proliferative phase consisting nearly $22 \%$. All the patients with late proliferative phase underwent hysterectomy with Histopathology showing proliferative endometrium of the hysterectomized specimen.

As shown in Table 4, in patients of AUB, out of 17 those with fibroids, 29\% went for hysterectomy, nearly $59 \%$ went for hysterectomy in Adenomyosis group and nearly $11 \%$ in endometrial hyperplasis group.

Table 5: Percentage of patients who were lost to follow up.

\begin{tabular}{|llll|}
\hline Diagnosis & Lost to Follw Up & $\%$ & p value \\
\cline { 1 - 2 } AUB & 2 & 50.00 & \\
\cline { 1 - 2 } DUB & 2 & 50.00 & \multirow{2}{*}{ NA } \\
\cline { 1 - 3 } Total & 4 & 100.00 & \\
\hline
\end{tabular}

As in Table 5, there were 4 patients among all i.e. $8 \%$ each in AUB and DUB group who didn't come for follow up visit. The response of the drug in these patients is not known.

Table 6: Percentage of patients with co-morbid condition in each group.

\begin{tabular}{|c|c|c|c|}
\hline & $\begin{array}{l}\text { Comorbid condition } \\
\text { (HTN, DM) }\end{array}$ & $\mathbf{N}$ & $\%$ \\
\hline DUB & & 4 & 8.00 \\
\hline AUB & & 2 & 4.00 \\
\hline
\end{tabular}

Table 6 demonstrates the drug was helpful in controlling menorrhagia, even in patients with co-morbid medical conditions, which consisted of $12 \%$ of the total patients like hypertension, DM and helped avert major surgery.

Table 7: Side effects of drug centchroman in both groups.

\begin{tabular}{|lll|}
\hline Side effects & N & Percentage \\
\hline Intermenstrual spotting & 15 & 30.00 \\
\hline Amenorrhoea & 4 & 8.00 \\
\hline Skin rash & 1 & 2.00 \\
\hline
\end{tabular}

As per Table 7, the most common side effect encountered was breakthrough spotting in $30 \%$ of patients, $8 \%$ complained of amenorrhoea after 3 months of taking this drug and $2 \%$ of patient complained of itching and rash over the body.

\section{DISCUSSION}

Centchroman is a well known drug for its contraceptive properties. Its action on the endometrium causing thinning of the endometrium preventing implantation is well documented. Its use in DUB has also been supported by authors. ${ }^{5-7}$
In this study we have used Centchroman as the treatment modality of DUB and AUB (above mentioned conditions). The only pre-requisite was the endometrium should be in proliferative phase in DUB and preferably in AUB cases which was confirmed after D and C. All these patients were multipara and complained of menorrhagia and were in reproductive age group. The mean age was around 40 years in both groups. Most of the DUB patients, $75 \%$ were relieved on medication whereas in AUB group only few found effect of this drug on their symptoms.

However, few of them who had poor response to drug went for hysterectomy. It was observed that patients with early proliferative phase on HPE had better response of this drug as compared with late proliferative phase. All the patients with late proliferative phase underwent hysterectomy. This relation was however found to be coincidental.

In patients of AUB, those with fibroids, $29 \%$ irrespective of size were relieved of menorrhagia with this drug. The other symptoms like pain in abdomen and heaviness in the lower abdomen remained the same. As this drug has anti oestrogenic effect on uterus and breast tissue, the fibroid remains static. There is no decrease in the size of fibroid but it prevents further growth by reducing endometrial thickness by effect on endometrial estrogen receptor $(\mathrm{ER}){ }^{8}$

Second possible explanation for effect on fibroid offered, is, that anti estrogenic effect, by default exerted a progestational effect on fibroid, to reduce vascularity and thereby reduce blood loss, as the latest theory suggests progesterone dependence of fibroid, as is on oestrogen according to original theory. ${ }^{9}$

In the cases of AUB with adenomyosis, this drug had no effect and these patients underwent hysterectomy after 3 months of therapy, without any fruitful result. This was mainly due to increased uterine cavity volume which is associated with endometrial hyperplasia and inadequate uterine contraction. This leads to distortion of junctional zone, there is no evidence of proliferative endometrial tissue and hence no role of centchroman. ${ }^{10}$

In patients of endometrial hyperplasia which was nearly $12 \%$ of the AUB patients, this drug showed poor response. The endometrial thickness in these 2 patients were $18 \mathrm{~mm}$ and $20 \mathrm{~mm}$ respectively as per ultrasonography finding. Its anti oestrogenic effect did help in reducing the endometrial thickness but the response was slow, so these patients opted for hysterectomy after 3 months of treatment.

On analysing the histopathology report of hysterectomized specimen, 5 patients in the DUB group had proliferative endometrium, 5 patients had leiomyoma in the myometrium with cervicitis and proliferative endometrium, 7 patients with adenomyosis had 
adenomyotic changes in the myometrium and 2 with endometrial hyperplasia had hyperplasia without atypia. So, this can be stated that centchroman was effective in relieving menorrhagia in the proliferative phase following $\mathrm{D}$ and $\mathrm{C}$ mostly in DUB patients. But certain type of hyperplasia was too resistant to be relieved by this drug. Whereas in AUB cases, it could control menorrhagia in fibroid patients. However, it was in effective in other uterine pathology e.g. adenomyosis and endometrial hyperplasia.

$8 \%$ of the total patients didn't come for follow up visit. The response of the drug in these patients is not known.

The drug was helpful in controlling menorrhagia, even in patients with co morbid medical conditions, which consisted of $12 \%$ of the total patients like hypertension, DM and helped avert surgical intervention and thus can be a modality of treatment for menorrhagia for such patients.

Centchroman is relatively a safe drug. The most common side effect encountered was breakthrough spotting in $30 \%$ of total patients under study, $8 \%$ patients complained of amenorrhoea after 3 months of taking this drug and $2 \%$ patient complained of itching and rash over the body. Rest of the patients who were relieved on medication did not complain of any side effect with this drug.

This study is at par with study of Kripalani et al, who studied the efficacy and the safety of Ormeloxifene in the management of menorrhagia: it was a pilot study and it was found that Ormeloxifene was an effective and a safe therapeutic option for the medical management of menorrhagia 5 and a study by Dhananjay BS et al on the role of sevista in the management of dysfunctional uterine bleeding, reported almost parallel results. ${ }^{6}$

The study sample is relatively small. A bigger sample size would have made the result more dependable and reliable.

\section{CONCLUSION}

Centchroman can be an effectively non-hormonal drug used for menorrhagia with proliferative endometrium with early changes in patients of DUB. This drug can also be used to control menorrhagia in patients with fibroid. This is also beneficial in patients with menorrhagia with medical illness to avert hysterectomy.
Funding: No funding sources

Conflict of interest: None declared

Ethical approval: The study was approved by the Institutional Ethics Committee

\section{REFERENCES}

1. Hoffman BL, Schorge JO, Bradshaw KaD, Halvorson LM, Schaffer JI, Corton MM. Williams Gynecology. $3^{\text {rd }}$ Ed. Published: McGraw-Hill Education / Medical;2016.

2. Munro MG, Critchley HO, Broder MS, Fraser IS. FIGO classification system (PALM-COEIN) for causes of abnormal uterine bleeding in nongravid women of reproductive age. Int $\mathbf{J}$ Gynecol Obstet. 2011 Apr;113(1):3-13.

3. Lal J. Clinical pharmacokinetics and interaction of centchroman-A mini review. Contraception. 2010 Apr 1;81(4):275-80.

4. Rajswaroob U, Kannan R, Kannnan NS, Tirouaroul T. Effectiveness of centchroman on regression of fibroadenosis and mastalgia. JCDR. 2016 Oct;10(10):PC10.

5. Kriplani A, Kulshrestha V, Agarwal N. The efficacy and safety of ormeloxifene in the management of menorrhagia: a pilot study. J Obstet Gynaecol. 2009;35(4):746-52.

6. Dhananjay BS, Nanda SK. The role of sevista in the management of dysfunctional uterine bleeding. JCDR. 2013 Jan;7(1):132.

7. Makker A, Tandon I, Goel MM, Singh M, Singh MM. Effect of ormeloxifene, a selective estrogen receptor modulator, on biomarkers of endometrial receptivity and pinopode development and its relation to fertility and infertility in Indian subjects. Fertility and sterility. 2009 Jun 1;91(6):2298-307.

8. Srilakshmi B. Ormeloxifene in DUB. Int J Curr Res. 2015;6(12).

9. Borahay MA, Asoglu MR, Mas A, Adam S, Kilic GS, Al-Hendy A. Estrogen receptors and signaling in fibroids: Role in pathobiology and therapeutic implications. Reprod Sci. 2017 Sep;24(9):1235-44.

10. Devi LT, Nimonkar R. Ormeloxifene in the management of dysfunctional uterine bleeding. Int $\mathbf{J}$ Reprod Contracept Obstet Gynecol. 2018;7:1885-92.

Cite this article as: Chandrayan $\mathrm{P}$, Naik FH, Desai DA. Centchroman use in dysfunctional and abnormal uterine bleeding after D and C. Int J Reprod Contracept Obstet Gynecol 2018;7:3502-6. 